\title{
Assessment of household use of iodized salt and adequacy of salt iodization: a cross-sectional National Study in Saudi Arabia
}

Mushary H. Al-Dakheel ${ }^{1}$, Hassan K. Haridi ${ }^{1 *}$, Bushra M. Al-Bashir ${ }^{1}$, Ali M. AL-Shangiti ${ }^{1}$, Sulaiman N. Al-Shehri ${ }^{2}$ and Izzeldin Hussein ${ }^{3,4}$

\begin{abstract}
Objectives: This study was conducted to assess household coverage with iodized salt in Saudi Arabia, and to determine adequacy of salt iodization.

Methods: A school-based cross-sectional study using WHO 30-cluster survey methodology.

Results: Analysis of 4242 salt samples using qualitative rapid test kit (RTK) revealed that $68.7 \%$ (95\% Cl 67.3-70.1\%) were iodized with significant regional differences $(p<0.001)$. The highest iodized salt samples came from Makkah (82.3\%), Riyadh (81.1\%) and Maddinah (76.2\%) regions, while the least iodized salt samples came from Hail (31.3\%), Baha (53.0\%), and Northern Borders (57.5\%) regions. The national weighted proportion of households consuming iodizes salt was $69.8 \%$ (95\% Cl 69.4-71.2), which is below the Universal Salt lodization (USI) goal ( $\geq 90 \%$ coverage). For validation, a quantitative iodometric titration method was used to analyze 775 representative salt samples screened iodized by RTK; iodine content of $\geq 15$ ppm was found in $95.2 \%$ (95\% Cl 93.9-96.5) of samples with median iodine content 51 ppm (mean $50.4 \pm 21.8$ ). More than $70 \%$ of the iodized salt samples contained iodine concentration higher than the recommended national level (15-40 ppm).
\end{abstract}

Conclusions: The study revealed inadequate consumption of iodized salt among Saudi households and explored marked regional heterogeneity. The majority of iodized salt samples contained iodine concentration more than the recommended level. These findings imply the need to launch a public awareness campaign on use of iodized salt. Legislation to ban production and sale of non-iodized salt sale for human consumption might be considered. A well-functioning monitoring system at factory level and surveillance system are crucially needed to ensure proper salt iodization and intake.

Keywords: lodized salt, Household, Saudi Arabia

\section{Introduction}

Iodine is essential for healthy brain development in the fetus and young child. Iodine deficiency negatively affects the health of women, as well as economic productivity and quality of life. It is the most common cause of preventable mental impairment throughout the world [1]. It has become very recognized that the consequences of

\footnotetext{
* Correspondence: hassankasim@hotmail.com

${ }^{1}$ Ministry of Health, Riyadh, Kingdom of Saudi Arabia

Full list of author information is available at the end of the article
}

iodine deficiency, including impaired brain development and low IQ in children, and nodules and hyperthyroidism in adults, can occur in the absence of clinical manifestation, such as cretinism and goiter [2]. Worldwide, it is estimated that one third $(\sim 1.88$ billion) of the world population lives in areas where natural sources of iodine are low, with approximately 29.8\% (241 million) school-age children globally are estimated to have insufficient intake of iodine [3]. There has been remarkable progress in the global effort to eliminate IDD. In 1993, WHO estimated that 
the prevalence of goiter due to iodine deficiency affected 110 countries globally. Over the past decade, the number of iodine-deficient countries has fallen from 54 to 25 and the number of countries with adequate iodine intake has increased from 67 to 116 [2].

Despite the scarcity of substantial historical data on iodine deficiency in Saudi Arabia, the two national surveys, carried out nearly two decades apart, have shown that Saudi population has a sufficient iodine nutrition at the national level, however, both surveys and other regional studies demonstrated a degree of mild to moderate iodine deficiency especially in the southern regions based in goiter prevalence indicator [4-7].

Food fortification is a public health policy aims to reduce the number of people with dietary deficiencies within a population. Salt is a good vehicle for iodization because it is consumed almost universally without seasonal variation; there are relatively few production facilities, simplifying quality control; technology for iodization is well established; consumer acceptability of iodized salt is high; and iodization is very inexpensive [8].

Universal Salt Iodization (USI) is a strategy recommended by the WHO and UNICEF Joint Committee on Health Policy since 1994 to ensure sufficient intake of iodine by all individuals. It indicate that all food-grade salt, used in household and food processing should be fortified with iodine as a safe and effective strategy for the prevention and control of iodine deficiency disorders in populations living in stable and emergency settings $[1,9]$. This strategy has been implemented in more than 120 countries around the world, many of them have successfully eliminated iodine deficiency disorders or made substantial progress in their control $[2,10]$. Saudi Arabia adopted this strategy as a recommendation of the first national survey about iodine deficiency disorders among Saudi population in 1994-1995 [4]. Salt iodization begins first at the level 70-100 ppm [11], then subsequently adjusted to a level of 15-40 ppm [12] responding to WHO recommendation [13].

Households coverage with iodized salt and monitoring quality of salt iodization are important key indicators in the implementations of USI programs [10]. Mapping disparities in household consumption of iodized salt and identifying areas with least coverage rates helps USI programs to target these areas. No data was available about household's coverage with iodized salt and adequacy of salt iodization at the national level in Saudi Arabia; these were not a part of data collection in the 1994-1995 national survey [4]. The present study aimed to estimate the proportion of households consuming iodized salt in Saudi Arabia at the national and regional levels and to assess the adequacy of salt iodization.

\section{Methods}

This study was based on the dataset of the National Survey on Iodine Deficiency Disorders conducted in 2012, which provided valuable information on the situation of iodine nutrition status in Saudi Arabia [5]. The survey was a cross-sectional school-based study adopted the ' 30 cluster' sampling methodology recommended by WHO/UNICEF/ICCIDD [14].

\section{Setting}

The Kingdom of Saudi Arabia (KSA) is widespread country constituting the bulk of the Arabian Peninsula with a land area of nearly two million $\mathrm{km}^{2}$. The land is primarily desert with rugged mountains in the southwest. The country is broadly divided into five geographicalareas, represented by the Central, Eastern, Western, Northern and Southern provinces with thirteen administrative regions. Central province includes, Riyadh and Qaseem regions; Western province includes, Makkah and Maddinah regions; Eastern province includes Eastern region; Northern province includes, Hail, Jouf, Northern Borders and Tabouk regions and Southern province includes, Aseer, Jizan, Baha and Najran regions. The population estimation according to 2010 census was $\sim 27$ million [15].

\section{Study population and sampling}

Nearly a 100\% primary school enrollment for both sexes in Saudi Arabia [16], making the school setting appropriate for ascertaining population-representative samples of children.

School children aged 8-10 years was the target population of this survey. Sampling frame of the study included all primary schools of the country (public and private) with a total of 13,626 schools, representing the primary sampling units (PSUs) [16].

Three stage random sampling was employed. In the first stage; the country was stratified into the five basic geographical areas; the Central, Eastern, Western, Northern and Southern provinces in order to carry out a separate subnational survey for each geographical area. In the second stage, a probability proportionate to size (PPS) sampling method was employed; thirty clusters were drawn randomly from the list of the PSUs in each geographical area. Every cluster represented a pair of schools; a male school and its neighbor female one, since schools in Saudi Arabia are unisex. In the third stage, thirty children for every cluster were chosen at random by systematic random technique, of whom, fifteen males and fifteen females children. Sample size for every geographical area survey was calculated at $(n=769)$ on the ground of an absolute precision of $\pm 5 \%$ with $95 \%$ confidence interval and design effect of 2 for anticipated 50\% iodized salt use among households (to maximize sample 
size, since we expected large regional disparities). Sample size was increased by $10 \%$ more to compensate for non-response.

A total of 30 clusters for every geographical area was completed, with 932, 968, 683, 1029 and 617 salt samples were collected from central, western, eastern, northern and southern provinces respectively (Table 1 ).

\section{Data collection}

Data on participant age, gender, educational class, locality were collected. Salt samples of about $20 \mathrm{~g}$ of routinely consumed salt, were collected by requesting all participants to bring from their homes. A clean air tight plastic pouch was provided to each enrolled child for this, so that there was no loss of iodine during sample transport. Each salt sample was screened qualitatively for iodine content using a rapid salt testing kits (RTK) [17]. These consist of a stabilized starch-based solution. One drop of the solution dripped on a teaspoon of salt containing iodine produces a blue/purple color change. Coloration indicates that iodine is present $>15 \mathrm{ppm}$ with inability to accurately identify salt iodized at $<15 \mathrm{mg} / \mathrm{kg}$ of iodine. In addition, the rapid test kits cannot identify overiodized salt at concentrations that may exceed 80$100 \mathrm{mg} / \mathrm{kg}$ [3]. Salt samples were classified qualitatively as iodized or non-iodized. From the samples identified as iodized by the RTK, $25 \%$ were randomly selected for iodine level determination using the quantitative iodometric titration method [17]. One person analyzed all the samples in duplicate. Adequately iodized salt was operationally defined as the salt containing $15 \mathrm{ppm}$ of iodine or more for reporting RTK results, however, a well-functioning iodization is indicated when iodine concentration in salt of $15-40 \mathrm{ppm}$ was met by iodometric titration method [17]. All reagents and salt analysis were done centrally under quality control measures in the Central Laboratory for Nutrition in Riyadh.

Table 1 Sample distribution and results of 4242 salt samples screened for iodine content by rapid test kit (RTK) classified by the five geographical provinces and the 13 administrative regions in Saudi Arabia, 2012

\begin{tabular}{|c|c|c|c|}
\hline Locality & No. of Clusters & No. of Salt Samples & \% lodized salt by RTK (95\% Cl) \\
\hline \multicolumn{4}{|c|}{ Regions in Central Province } \\
\hline - Riyadh & 24 & 718 & $81.1(78.0-83.8)$ \\
\hline - Qaseem & 6 & 214 & $75.2(68.9-80.9)$ \\
\hline Total & 30 & 932 & $79.7(77.0-82.2)$ \\
\hline \multicolumn{4}{|c|}{ Regions in Western Province } \\
\hline - Makkah & 22 & 691 & $82.3(79.2-85.1)$ \\
\hline - Maddinah & 8 & 277 & $76.2(70.7-81.1)$ \\
\hline Total & 30 & 968 & $80.6(77.9-83.0)$ \\
\hline \multicolumn{4}{|c|}{ Regions in Eastern Province } \\
\hline Total & 30 & 683 & $63.8(60.1-67.4)$ \\
\hline \multicolumn{4}{|c|}{ Regions in Northern Province } \\
\hline - Hail & 8 & 294 & $31.3(26.0-36.9)$ \\
\hline - Northern Borders & 5 & 186 & $57.5(50.1-64.7)$ \\
\hline - Tabouk & 11 & 354 & $66.7(61.5-71.6)$ \\
\hline - Jouf & 6 & 208 & $60.6(53.6-67.3)$ \\
\hline Total & 30 & 1042 & $53.8(50.8-56.9)$ \\
\hline \multicolumn{4}{|c|}{ Regions in Southern Province } \\
\hline - Jizan & 11 & 224 & $66.5(59.9-72.7)$ \\
\hline - Asseer & 13 & 173 & $61.8(54.2-69.1)$ \\
\hline - Baha & 3 & 117 & $53.0(43.5-62.3)$ \\
\hline - Najran & 3 & 103 & $74.8(65.2-82.8)$ \\
\hline Total & 30 & 617 & $64.0(60.1-67.8)$ \\
\hline \multirow[t]{2}{*}{ National } & 150 & 4242 & $68.7(67.3-70.1)$ \\
\hline & & & $69.8(69.4-71.2)^{a}$ \\
\hline
\end{tabular}

Abbreviations: $R T K$ rapid test kit; $C l$ confidence interval

${ }^{a}$ Adjusted national estimate to account for regional population weights

There was a significant difference in iodized salt samples among geographical provinces $\left(X^{2}=237.1 ; \mathrm{df}=4 ; P<0.001\right)$ 


\section{Statistical analysis}

Data processing and statistical analyses were performed using the Epi Info statistical package version 7 (CDC, Atlanta, GA, USA). General tabulation including frequency distribution were used with $95 \%$ confidence interval (CI). Salt iodine concentration and other continuous variables were expressed in median with interquartile range $(\mathrm{IQR})$ and mean $( \pm \mathrm{SD})$. Chi-square test was used to test for differences in proportions. National estimates of coverage were weighted according to the total number of children per region compared to the national total. Analysis for complex sampling design took into consideration sampling stratification, clustering and regional weights and permitting estimates adjustment. The mean iodine concentration measured by iodometric titration for salt subsample was calculated in simple arithmetic for regional and national estimates. All tests were two-sided and the level of significance was set at $p<0.05$.

\section{Ethical considerations}

The ethical issues of this study was reviewed and approved by the Ethical Committee of the Ministry of Health, KSA. Approval of Education Authority was obtained. A written informed consent was obtained from the parents/guardians of participating children.

\section{Results}

Out of the total of 4242 salt samples collected, $68.7 \%$ (95\% CI 67.3-70.1\%) were found iodized using rapid test kit (RTK) (Table 1), with significant provincial differences $(p<0.001)$. The northern province had the lowest percent (53.8\%) of iodized salt samples, whereas western province was the highest (80.6\%). At the level of administrative regions; significant differences $(p<0.001)$ were observed in iodized household salt use, varying from highest $82.3 \%$ in Makkah region, $81.1 \%$ in Riyadh region, $76.2 \%$ in Maddinah region, together have more than half of population weight of the country to least proportions of households consuming iodized salt as 31.3\%, 53.0\% and $57.5 \%$ for Hail, Baha and Northern Borders regions respectively (Table 1 ), all of them have a limited population weights.

Iodometric titration method was used for validation of iodine content in samples tested by the RTK. A representative sample $(n=775)$ from the total samples screened positive for iodine by RTK were tested. The results revealed adequate ( $\geq 15 \mathrm{ppm}$ ) iodine content of salt in "95.2\%" (95\% CI 93.9-96.5) of the samples, with a mean \pm SD $50.4 \pm 21.8$ and median 51 ppm concentration (Table 2). There was a significant difference in iodine content of iodized salt samples among different geographic provinces $(P<0.001)$. The proportion of households consuming adequately iodized salt was estimated at: $75.9 \%$ (95\% CI 73.2-78.7), 76.7\% (95\% CI 74.0-79.4), $60.7 \%$ (95\% CI 57.0-64.4), 51.2\% (9\% CI 48.2-54.2), and 60.9\% (95\% CI 57.1-64.8) for Central, Western, Eastern, Northern and Southern provinces respectively, with weighted national estimate at $69.8 \%$ (95\% CI 68.4-71.2). An important finding in Table 2 shows that more than two third (70.7\%) of the overall iodized salt samples analyzed by the quantitative iodometric titration method exceeded the upper level of the national recommended level of iodine salt concentration (15-40 ppm) iodine. Percentage of salt samples overiodized with iodine content $>40 \mathrm{ppm}$ were $55.2 \%$, $84.1 \%, 66.9 \%, 73.1 \%$, and $76.0 \%$ for Central, Western, Eastern, Northern and Southern provinces respectively.

\section{Discussion}

In an effort to elucidate the coverage and quality of iodized salt use among households in Saudi Arabia, we conducted the present national cross-sectional survey. Our results underscored three significant findings with implication to the national USI program: (1) a national coverage below the USI target; (2) coverage varies considerably between regions; and (3) improper salt iodization.

To our knowledge, this study is the first to report national representative data on household coverage with adequately iodized salt in Saudi Arabia. Before this survey a scarce data on the households' coverage with iodized salt were only identified, coming from few regional studies and revealed a wide range of coverage. A report from Hail at the north of Saudi Arabia (2004); described the pattern of household salt consumption and pointed to the prevalent pattern of consumption of the non-iodized salt in that area. Only $27.7 \%$ of households were consuming iodized salt as an exclusive source of salt, $31.6 \%$ were consuming non iodized salt, while $40.7 \%$ were consuming iodized salt as a table salt and not for cooking purposes (Haridi HK et al.: Project Early Detection \& Health Education of Thyroid Cancer in Hail, 2004, unpublished). On the other hand, at the southern province, a study in Jizan region, 2010, reported almost all households were consuming iodized salt [6]. A recent study from Aseer region at southern province, reported $77.5 \%$ coverage rate [7].

The first significant findings in our study is that: despite the relatively reasonable coverage at the national level where $69.8 \%$ of households were consuming iodized salt, yet, it is still far from the criterion $90 \%$ coverage of USI goal by WHO [17]. This coverage is comparable to the neighbor Oman (68.5\%), higher than Sudan (9.5\%), Morocco (21.2) and Yemen (29.5\%), but lower than Egypt (77.7\%), Lebanon (74.8\%) and Tunisia (96.7\%) [18]. 
Table 2 lodine content of salt tested by iodometric titration method in a representative salt sample $(\mathrm{n}=775)$ positive for iodine content by rapid test kit (RTK) at different geographical provinces and national level in Saudi Arabia, 2012

\begin{tabular}{|c|c|c|c|c|c|c|}
\hline \multirow{2}{*}{$\begin{array}{l}\text { Geographical } \\
\text { areas }\end{array}$} & \multirow{2}{*}{$\begin{array}{l}\text { No. of } \\
\text { Salt } \\
\text { Samples }\end{array}$} & \multicolumn{3}{|c|}{$\%$ of salt samples at various iodine concentrations (ppm) } & \multirow[t]{2}{*}{ Mean (SD) } & \multirow[t]{2}{*}{ Median (IQR) } \\
\hline & & $<15$ & $15-40$ & $>40$ & & \\
\hline Central province & 172 & 7.0 & 37.8 & 55.2 & $42.76(21.30)$ & $43.5(27.0-54.0)$ \\
\hline Western province & 182 & 1.6 & 14.3 & 84.1 & $54.32(16.88)$ & $53.0(44.0-65.0)$ \\
\hline Eastern province & 142 & 12.7 & 20.4 & 66.9 & $51.33(27.91)$ & $54.0(29.0-69.0)$ \\
\hline Northern province & 154 & 1.3 & 25.6 & 73.1 & $52.10(21.05)$ & $52.0(38.0-64.0)$ \\
\hline Southern province & 125 & 0.0 & 24.0 & 76.0 & $52.44(18.98)$ & $51.0(41.0-64.0)$ \\
\hline National & 775 & 4.8 & 24.5 & 70.7 & $50.40(21.80)$ & $51.0(37.0-63.0)$ \\
\hline
\end{tabular}

Abbreviations: RTK rapid test kit; SD Standard Deviation; IQR Interquartile Range $25 \%-75 \%$

There was a significant difference in iodized salt samples among regions $\left(X^{2}=68.42 ; \mathrm{df}=8 ; P<0.001\right)$.

National production of iodized salt in Saudi Arabia is high exceeds the domestic demand and exported to the international market. Salt production in Saudi Arabia was about two million metric tons in 2012 according to British Geological survey and ranked 23 in the leading salt producers worldwide [19]. As an open market, the imported iodized salt in Saudi Arabia is also available. Both local and imported iodized salt have an affordable price.

Regulations in Saudi Arabia are not banning the production and distribution of non-iodized salt. Availability and easy accessibility to coarse non iodized salt, with low price and big quantity packages competes the exclusive availability of the iodized salt and impedes the achievement of the recommended USI goal. The coarse salt available in the market is produced locally from desert salt lakes or rocky salt. It is very deficient or have no iodine and traditionally consumed by households for many decades and considering it as natural and tasty. This imply that public awareness campaigns about the importance of iodized salt is especially needed in areas where non iodized salt use is common. Legislation to ban the non-iodized salt sale may be of value and proved effective in other countries [20].

The second significant findings in our study is the wide regional disparities in iodized salt use among households, with none of the 13 regions in the country attained WHO/UNICEF/ICCIDD USI criterion of " $\geq 90 \%$ of households consuming adequately iodized salt" [17]. Inequalities in coverage ranged between $31.3 \%$ in Hail region at the Northern province to $82.3 \%$ in Makkah region at Western province. This marked regional variation imply the need to study factors affecting such disparities in terms access, demand and preferences of households as regard salt consumption. Worth noting that most regions with low iodized salt use were low density population regions and the highest coverage was in the central and western regions, the highly populated.

The third significant findings in our study is the excess amount of iodine in iodized salt that exceeds the range of the recommended fortification (15-40 ppm). The iodine content of iodized salt measured by iodometric titration method, revealed $51 \mathrm{ppm}$ median (mean 50.4 \pm $21.8)$, with more than two third $(70.7 \%)$ of iodized salt samples contained more than $40 \mathrm{ppm}$ iodine which may leads to iodine over intake with a risk of adverse health consequences like iodine-induced hyperthyroidism and autoimmune thyroid diseases $[10,13,17,21]$. This draws the attention to the need for a good monitoring system to ensure commitment and proper quality control systems of salt producers. Several salt producers, still marketing salt with iodine according to the previous code $(70-100 \mathrm{ppm})$. It is essential to change legislation to mandate the iodine salt adjustment (15-40 ppm) instead of just recommending it.

Lessons from international experience indicated that policies, laws, and agreements requiring all edible salt to be iodized, effective inspection and enforcement systems, and political advocacy and scientific support from community leaders are critical to any national iodine deficiency disorders elimination program requiring salt iodization [2]. Helping small-scale producers of the noniodized coarse salt in qualifying the process of production and fortifying their product by the recommended amount of iodine, may be helpful in rapid achieving the goal of the iodized salt full coverage.

Despite the known benefits of appropriate consumption of iodine, some concern exists that widespread salt iodization could potentially lead to excess iodine intake [21]. Monitoring of food-grade salt quality is essential to ensure both efficacy and safety of the process of iodine fortification [10]. On the other hand, as populations reduce salt intake to reduce the risk of elevated blood pressure, hypertension and stroke, there may be increase in iodine deficiency disorders [22, 23]. It is crucial to recognize that salt reduction and salt iodization strategies are not contradictory [24]. As salt consumption is reduced, iodine levels should be increased to ensure populations continue to consume enough iodine. Meanwhile, the objective of salt iodization programs is not to 
encourage increased consumption of salt but to ensure it is all iodized [24].

The strength of the present study is being conducted in five separate subnational provincial surveys that allowed for better regional mapping of the households' coverage with iodized salt. However, our study might have had some limitations: First, we experienced some difficulty to recruit the ideal number of children in some clusters in Jizan at the southern province because of high absenteeism due to heavy rain during the survey time. Yet, the small number of clusters and limited population weight of the locality does not compromise our general interpretation of the results. Second, the study did not explore factors affecting household consumption of iodized salt, which will be addressed in a subsequent household survey, focusing on regions with least coverage. We acknowledge that the present study is somewhat dated and may not reflect the current situation with regard to salt iodization in Saudi Arabia. However, the information contributes to the process of periodic assessment of the progress towards USI efforts in the country.

\section{Conclusion}

The study highlighted inadequate consumption of iodized salt among Saudi households and explored regional heterogeneity. The majority of iodized salt samples contained iodine concentration more than the recommended level. These results, suggests the need to ban non-iodized salt sale and to launch community awareness campaigns especially in areas where non-iodized salt use is common. Establishing a proper monitoring system at factory level and surveillance system are crucially needed to ensure proper salt iodization and intake.

\section{Acknowledgements}

We would like to thank all those who facilitated this study at the Ministry of Health and Ministry of Education, Saudi Arabia. Special thanks are due to all medical staff who actively participated in the field work.

\section{Funding}

None.

Availability of data and materials

Please contact author for data request.

\section{Authors' contributions}

MA study conception and design, supervised the work and edited the paper; $\mathrm{HH}$ study design, analyzed the data and wrote the paper; BB collected samples and participated in data analysis; AA laboratory analysis; SA ensured proper sample distribution; $I H$ participated in the study design. All authors had intellectual inputs into discussion and interpretation of results and critically revised the article for important intellectual content. All authors read and approved the final manuscript.

\section{Ethics approval and consent to participate}

The ethical issues of this study was reviewed and approved by the Ethical Committee of the Ministry of Health, KSA. Approval of Education Authority was obtained. A written informed consent was obtained from the parents/ guardians of participating children.
Consent for publication

Not applicable.

\section{Competing interests}

The authors declare that they have no competing interests.

\section{Publisher's Note}

Springer Nature remains neutral with regard to jurisdictional claims in published maps and institutional affiliations.

\section{Author details}

${ }^{1}$ Ministry of Health, Riyadh, Kingdom of Saudi Arabia. ${ }^{2}$ Ministry of Education, Riyadh, Kingdom of Saudi Arabia. ${ }^{3}$ Lipidomics and Nutrition Research Centre, London Metropolitan University, London, UK. ${ }^{4}$ Iodine Global Network (IGN), Zürich, Switzerland.

Received: 14 September 2017 Accepted: 16 February 2018

Published online: 28 February 2018

\section{References}

1. WHO. lodization of salt for the prevention and control of iodine deficiency disorders. Available at: http://www.who.int/elena/titles/salt_iodization/en/\# (Accessed July 5, 2016).

2. UNICEF/EAPRO East Asia and Pacific Regional Office. The East Asia Pacific Regional Workshop on Achievement of Universal Salt lodization for Optimal lodine Nutrition: A Meeting Report. Bangkok, Thailand, 12-14 October 2015. UNICEF; 2016.Availabe at: http://www.unicef.org/eapro/East_Asia_Pacific_ Regional_Workshop_on_Achievement_of_Universal_Salt_lodization_for_ Optimal_lodine_Nutrition.pdf (Accessed 5 July 2016).

3. Rohner F, Zimmermann M, Jooste P, Pandav C, Caldwell K, Raghavan, et al. Biomarkers of nutrition for development-iodine review. J Nutr. 2014;144(8):1322S-42S. https://doi.org/10.3945/jn.113.181974.

4. Al-Nuaim AR, Al-Mazrou Y, Kamel M, Al-Attas O, Al-Daghari N, Sulimani R. lodine deficiency in Saudi Arabia. Ann Saudi Med 1997 May;17(3):293-297. PMID:17369725.

5. Al-Dakheel MH, Haridi HK, Al-Bashir BM, Al-Shingiti A, Al-Shehri S, Gassem MA, Hussein I. Prevalence of iodine deficiency disorders among school children in Saudi Arabia: results of a national iodine nutrition study. East Mediterr Health J. 2016;22(5):301-8.

6. Alsanosy R, Gaffar A, Khalafalla H, Mahfouz M, Zaid A, Bani I. Current iodine nutrition status and progress toward elimination of iodine deficiency disorders in Jazan, Saudi Arabia. BMC Public Health. 2012;12:1006.

7. Abbag Fl, Abu-Eshy SA, Mahfouz AA, Al-Fifi SA, El-Wadie H, Abdallah SM, et al. lodine-deficiency disorders in the Aseer region, south-western Saudi Arabia: 20 years after the national survey and universal salt iodization. Public Health Nutr 2015 Oct;18(14):2523-2529. doi: https://doi.org/10.1017/ S1368980014003073. Epub 2015 Jan 7.

8. Higgins JPT, Green S (editors). Cochrane Handbook for Systematic Reviews of Interventions Version 5.1.0 [updated March 2011]. The Cochrane Collaboration, 2011. Available at: http://handbook.cochrane.org. (Accessed 13 July 2016).

9. Aburto N, Abudou M, Candeias V, Wu T. Effect and Safety of salt iodization to prevent iodine deficiency disorders: a systematic review with metaanalyses. WHO eLibrary of evidence for nutrition actions (eLENA). Geneva: world health Organization. 2014;

10. WHO. Guidelines: fortification of food-grade salt with iodine for prevention and control of iodine deficiency disorders. Geneva: World Health Organization; 2014.

11. Saudi Standards, Metrology and Quality Organization (SASO). Food Grade Salt: GSO STANDARD. GSO 1843/2007. 2007. pp. 1-15.

12. Saudi Standards, Metrology and Quality Organization (SASO). Food Grade Salt: GSO STANDARD. GSO 1843/2010. 2010.pp. 1-9.

13. World Health Organization/UNICEF/International Council for the Control of lodine Deficiency Disorders. Recommended iodine levels in salt and guidelines for monitoring their adequacy and effectiveness. (WHO/ NUT/96.13). Geneva: WHO, 1996.

14. World Health Organization/United Nations Children's Fund/International Council for Control of lodine Deficiency Disorders. Elimination of iodine deficiency disorders: a manual for health workers. Cairo: WHO Regional Office for Eastern Mediterranean; 2008. 
15. Central Department of Statistics \& Information. KSA. General Census of Population and Housing, 2010. Available at: https://www.stats.gov.sa/en/13. Accessed 19 Sept 2014.

16. General Department for Planning and Statistics. Statistical summary report for male and female education report, 1429-1430 H. Riyadh: ministry of Education; 2009. [in Arabic].

17. World Health Organization/United Nations Children's fund/International Council for the Control of iodine deficiency disorders. Assessment of iodine deficiency disorders and monitoring their elimination. 3rd ed. Geneva: World Health Organization; 2007.

18. Iodine Global Network. Global lodine Nutrition Scorecard for 2015. Available at: http://www.ign.org/cm_data/Scorecard_2015_August_26_new.pdf. (Accessed 5 July 2016)

19. British Geological Survey (BGS). World Mineral Production 2010 to 2014. Available at: http://www.bgs.ac.uk/mineralsuk/statistics/worldArchive.html (Accessed 4/7/2016). file download: http://www.bgs.ac.uk/downloads/start. cfm?id=3084

20. Begin F, Codling K. lodized salt legislation in south and East Asia and the Pacific: an overview. IDD. Newsletter. 2013;41(2):16. http://www.ign.org/cm_ data/idd_may13_asia_salt_law.pdf. (Accessed 5 July 2016)

21. Salt as a vehicle for fortification. Report of a WHO expert consultation. Geneva: World Health Organization; 2008. Available at: http://www.who.int/ dietphysicalactivity/LUXsaltreport2008.pdf. (Accessed 5 July 2016).

22. Aburto NJ, Ziolkovska A, Hooper L, Elliott P, Cappuccio FP, Meerpohl J. Effect of lower sodium intake on health: systematic review and metaanalyses. BMJ. 2013:346:f1378. https://doi.org/10.1136/bmj.f1326.

23. Guideline: Sodium intake for adults and children. Geneva: World Health Organization; 2012. Available at: http://www.who.int/nutrition/publications/ guidelines/sodium_intake_printversion.pdf. (Accessed 5 July 2016).

24. WHO and the George Institute (2014). Salt reduction and iodine fortification strategies in public health Report of a joint technical meeting, 2014 Available at: http:/www.who.int/nutrition/publications/publichealth_ saltreduc_iodine_fortification/en/. (Accessed 23 July 2016).

\section{Submit your next manuscript to BioMed Central and we will help you at every step:}

- We accept pre-submission inquiries

- Our selector tool helps you to find the most relevant journal

- We provide round the clock customer support

- Convenient online submission

- Thorough peer review

- Inclusion in PubMed and all major indexing services

- Maximum visibility for your research

Submit your manuscript at www.biomedcentral.com/submit 